\title{
Research on the Reasonable Strengthening Time and Stability of Excavation Unloading Surrounding Rock of High-Stress Rock Mass
}

\author{
Wensong $X u \mathbb{D}^{1},{ }^{1,2}$ Wentao $X u^{1,2}$ and Yunhai Cheng ${ }^{1,2}$ \\ ${ }^{1}$ State Key Laboratory of Mining Response and Disaster Prevention and Control in Deep Coal Mines, Anhui University of Science \\ and Technology, Huainan 232001, China \\ ${ }^{2}$ School of Mining Engineering, Anhui University of Science and Technology, Huainan 232001, China
}

Correspondence should be addressed to Wensong Xu; 359879021@qq.com

Received 27 May 2021; Accepted 25 August 2021; Published 14 September 2021

Academic Editor: Yong-Zheng Wu

Copyright (C) 2021 Wensong Xu et al. This is an open access article distributed under the Creative Commons Attribution License, which permits unrestricted use, distribution, and reproduction in any medium, provided the original work is properly cited.

\begin{abstract}
This study is aimed at better understanding the deformation and failure mechanism of surrounding rock during excavation unloading of a high-stress rock mass and determining the reasonable reinforcement time for the surrounding rock. To fulfill this aim, true triaxial tests were carried out on different loading and unloading paths during the unilateral unloading of a high-stress rock mass. The variational condition for minimization of plastic complementary energy is obtained, the optimal reinforcement time is determined, and the range of the plastic zone in the surrounding rock reinforced by anchor mesh-cable-grouting is compared and analyzed. The results are as follows: (1) Based on the Mohr-Coulomb yield criterion and the deformation reinforcement theory of surrounding rock, the stable state with the minimum reinforcement force is obtained. (2) After the true triaxial tests on the unilateral unloading of the third principal stress were carried out under different confining pressures, loading continued to be performed. Compared with rock failure without confining pressure, in the conventional uniaxial compression test, the failure of samples is dominated by composite splitting-shear failure; the unilateral unloading stress-concentration failure is a progressive failure process of splitting into plates followed by cutting into blocks and then the ejection of blocks and pieces. (3) The relationship between the time steps of the surrounding rock stability and the excavation distance is obtained. The supporting time can be divided into four stages: presupport stage, bolt reinforcement stage, anchor cable reinforcement stage, and grouting reinforcement stage. (4) In the range of within $5 \mathrm{~m}$ behind the tunneling face, the plastic zone of the surrounding rock with support is reduced by $7 \mathrm{~m}$ as compared with that with no support. In the range of over $5 \mathrm{~m}$ behind the tunneling face, the plastic zone of the roadway floor with support is reduced by $2.6 \mathrm{~m}$ as compared with that without support, and the deformation is reduced by $90 \%$. These results can serve as a reference for controlling the behavior of surrounding rock during excavation unloading of high-stress rock masses.
\end{abstract}

\section{Introduction}

After roadway/tunnel excavation, the surrounding rock suffers deformation, thus resulting in stress redistribution. In the process of constant stress adjustment, the internal structure of the rock mass changes. With time, the stress in the surrounding rock near the excavated rock mass reaches its critical failure strength, and overall failure occurs $[1,2]$. Therefore, understanding the failure characteristics and determining the rational supporting time of surrounding rock near the excavated rock mass can help effectively control the deformation of surrounding rock [3-5].

There have been many studies on the stability of surrounding rock of underground roadways from the perspectives of stress, deformation, energy, etc. using various research methods [6-8]. Wu et al. [9] adopted a variety of research techniques to analyze the zonal deformation and failure characteristics and stress distribution characteristics of the roof, floor, two sides, and four corners of a tilted stratum roadway. Besides, the stability control technology 
for controlling the nonhomogeneous deformation of the tilted stratum roadway was proposed with engineering verification. Zhang and Han [10] analyzed the magnitude, direction change, and distribution characteristics of crustal stress in mines based on the measured crustal stress data in the mining areas and studied the influence of crustal stress on roadway stability; they provided a reliable basis for the design of a reasonable support structure for roadways. Gou et al. [11] investigated the effect of horizontal tectonic stress on the stability of surrounding rock of a roadway by numerical simulation and showed that with an increase in the horizontal stress, the horizontal stress transfers to the deeper parts of the roadway roof and floor; this causes floor heave and fold failure of the roadway and shear deformation and wedge caving of the roof, with deformation and failure of the roof and floor being greater than that of the two sides of the roadway. Li et al. [12] mainly analyzed the stress distribution, deformation, and failure mechanism of surrounding rock in deep parts by using the elastic-brittle constitutive model and sliding failure theory. Yang et al. [13] showed that the rotation angle of the main roof was the main factor leading to roof deformation; the roof convergence could not be reduced by strengthening the roadway support, and the roof convergence, as well as the fracture direction, could be effectively controlled by increasing the roof cutting height and angle. Yao [14] is of the opinion that the surrounding rock support of a roadway is closely related to the initial stress, excavation mode and progress, surrounding rock grade, etc. Han et al. [15] studied the stress characteristics of rock strata experiencing roof cutting and pressure relief and determined the key parameters of roof cutting height, roof cutting angle, and hole spacing based on the theoretical analysis method of mine ground pressure. They showed that the roof cutting could significantly reduce roadway stress and deformation and improve roadway support and production efficiency. $\mathrm{Xu}$ et al. [16, 17] conducted true triaxial tests to study the damage and fracture characteristics of marble under excavation unloading of a high-stress rock mass; they showed that for the excavation unloading surface, the main failure surface is near the free surface as the stress decreases. Dong et al. [18] studied the mechanical characteristics and failure mechanism of surrounding rock during excavation unloading of a deep circular roadway and established the strength criterion and a tension-compression damage model for dynamic unloading to obtain the failure characteristics of the excavation unloading surface. These scholars evaluated the failure characteristics, overall stability, and reasonable support structure of surrounding rock after excavation unloading of roadways from various perspectives; however, they did not propose a reasonable supporting time or specific measures according to the actual situation.

Based on the failure mechanism of the surrounding rock of roadways during excavation unloading, many scholars have put forward reasonable supporting times and supporting modes [19-21]. Su et al. [22] determined the primary support timing through the evolution of safety factors during tunnel excavation. Zhou et al. [23] analyzed the changes of stress in the plastic zone, displacement of the tunnel wall, and support pressure in the tunnel supporting process and proposed a reasonable supporting time for staged tunnel supporting. Sun and Zhang [24] put forward the layer model, obtaining the deformation process and supporting characteristics of the surrounding rock, and studied the synergistic supporting mechanism of the composite supporting layer. Yu [25] studied the space-time evolution of surrounding rock deformation under the disturbance of tunnel excavation and established a three-dimensional mechanical model to study the interaction between tunnel structure and surrounding rock. He also analyzed the supporting effects of various supporting structures and obtained the mechanical characteristics and practicability of composite supporting structures. Dong [26] and Hou et al. [27] mainly summarized three supporting technologies in terms of control technologies: the combined supporting technology with anchor bolt (cable) as the main part supplemented by other technologies, the integrated supporting technology with the integration of anchor bolt, and the combined technology with supports. However, they only analyzed the supporting effect from one aspect or through multiple ways and adopted a single or multiple supporting means for combined support; they, however, did not propose a reasonable supporting time and appropriate supporting mode from the optimal supporting time in different stages of surrounding rock of roadways under excavation unloading. Therefore, building on many previous studies, the reasonable supporting time and stability were explored in this study.

In this study, based on the Mohr-Coulomb yield criterion and the minimum plastic complementary energy, the failure and reinforcement time of surrounding rock were analyzed. True triaxial tests on different loading and unloading paths were conducted to investigate the stress failure characteristics of a rock mass during excavation unloading. Through 3DEC numerical simulation, the optimum supporting time for surrounding rock during excavation unloading at different stages was determined, and on-site verification was conducted.

\section{Theoretical Analysis on Surrounding Rock Reinforcement during Excavation Unloading}

2.1. Mohr-Coulomb Yield Criterion. According to the method of calculating the safety coefficient of points in surrounding rock based on the Mohr-Coulomb theory, the MohrCoulomb yield function is expressed by the principal stress as follows:

$$
f\left(\sigma_{1}, \sigma_{2}, \sigma_{3}\right)=\frac{1}{2}\left(\sigma_{1}-\sigma_{2}\right)-\frac{1}{2}\left(\sigma_{1}+\sigma_{3}\right) \sin \varphi-c \cos \varphi
$$

where $\sigma_{1}, \sigma_{2}, \sigma_{3}$ denote the first, second, and third principal stresses, respectively; $\varphi$ denotes internal friction angle; and $c$ denotes cohesion.

With the elastic theory as the basis, it is considered that yield occurs when the stress value meets certain conditions; 
to represent the safety degree of a rock mass, engineering researchers propose the concept of the safety coefficient [22]:

$$
F=\frac{H(\chi)}{f(\sigma)}
$$

where $H$ denotes material parameter, which is the function of the internal variable $\chi$ of scalar, and $F$ denotes the safety coefficient; $F>1$ indicates no yield inside the yield surface, $F=1$ indicates a critical state on the yield surface, and $F<$ 1 indicates shear failure outside the yield surface.

According to the Mohr-Coulomb yield criterion, the distance between the stress state at any point in the rock mass and the strength envelope curve is determined (shown in Figure 1).

If the strength envelope curve is translated downward, that is, corresponding to the reserve safety margin, then the safety coefficient based on the Mohr-Coulomb yield criterion is

$$
F=\frac{|A C|}{|A B|}=\frac{|A D| \cos \varphi}{|A B|}=\frac{c \cos \varphi+\left(\left(\sigma_{1}+\sigma_{3}\right) / 2\right) \sin \varphi}{\left(\sigma_{1}-\sigma_{3}\right) / 2}
$$

2.2. Deformation Reinforcement Theory of Surrounding Rock. It is supposed that for the action on an elastic-plastic structure, the body force is $f=f_{i}$, the stress boundary is $S_{\sigma}$, and the boundary condition is $T=T_{I}=\sigma_{i j} n_{j}$. Then, regarding any given virtual displacement $\delta u=\delta u_{i}$, the corresponding virtual strain is $\delta \varepsilon_{i j}$. Based on the virtual displacement principle, the following can be obtained:

$$
\int_{V} \delta \varepsilon_{i j} \sigma_{i j}^{1} \mathrm{~d} V=\int_{V} \delta u_{i} f_{i} \mathrm{~d} V+\int_{S_{\sigma}} \delta u_{i} T_{i} \mathrm{~d} S
$$

Considering any coordinated equilibrium stress field $\sigma_{1}$ and coordinated stable stress field $\sigma$, the difference between them is the plastic stress increment field $\Delta \sigma_{p}$ :

$$
\Delta \sigma_{p}=\sigma_{1}-\sigma
$$

Substitute Equation (5) into Equation (4), and through the transposition of terms, the following can be obtained:

$$
\begin{aligned}
\int_{V} \delta \varepsilon_{i j} \sigma_{i j} \mathrm{~d} V & =\int_{V} \delta u_{i} f_{i} \mathrm{~d} V+\int_{S_{\sigma}} \delta u_{i} T_{i} \mathrm{~d} S-\int_{V} \delta \varepsilon_{i j} \Delta \sigma_{i j}^{p} \mathrm{~d} V \\
\Delta \varepsilon^{p} & =\Delta \lambda \frac{\partial f}{\partial \sigma} \\
\Delta \varepsilon^{p} & =C: \Delta \sigma^{p}=C:\left(\sigma_{1}-\sigma\right)
\end{aligned}
$$

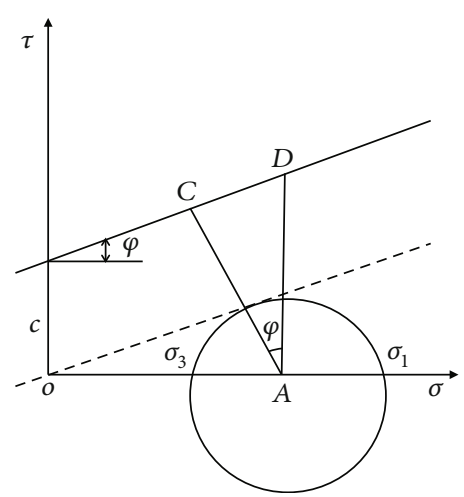

FIgURe 1: Calculation diagram for the safety coefficient of points based on Mohr-Coulomb theory.

By substituting Equation (8) into Equation (7) and noting that $\sigma$ is on the yield plane, the final stress state $\sigma$ can be determined, that is,

$$
C:\left(\sigma_{1}-\sigma\right)=\Delta \lambda \frac{\partial f}{\partial \sigma}, \quad f(\sigma)=0
$$

Due to the deformation compatibility characteristic of $\sigma_{1}$, it actually represents a certain deformation state. Therefore, Equation (6) can also be expressed as follows: an unstable deformation state can be stabilized by applying reinforcement force. There are many such reinforcement schemes. The stable stress field $\sigma$ in accordance with the plastic constitutive equation (orthogonal flow rule and consistency condition) is determined as follows: everywhere within $V 0$, $\sigma_{1}=\sigma$, and $\sigma$ is determined by using Equation (9) in each point within $V 1$. It is clear that the stable stress field $\sigma$ determined in this way is the stress field closest to the stress field $\sigma_{1}$ in the set $S$, i.e., $L$ or $\Delta E$ is the minimum.

Thus, an important conclusion can be drawn as follows: for a specific rock mass with an unstable deformation structure, the plastic constitutive relation makes the structure approach the nearest stable state, or the plastic constitutive relation makes the structure approach the stable state requiring the minimum reinforcement force. The variational condition for minimizing the plastic complementary energy is

$$
\delta(\Delta E)=0, \delta^{2}(\Delta E)>0
$$

For a specific rock mass with unstable deformation structure, it indicates $\delta \sigma_{1} \equiv 0$. Due to the positive definiteness of $C$, the second-order variation of the plastic complementary energy is constantly positive:

$$
\delta^{2}(\Delta E)=\int_{V} \delta \sigma: C: \delta \sigma \mathrm{d} C>0
$$

Thus, the following can be obtained:

$$
\begin{gathered}
\delta(\Delta E)=-\int_{V} \delta \sigma: C:\left(\sigma_{1}-\sigma\right) \mathrm{d} V=-\int_{V} \delta \sigma \\
: \Delta \varepsilon^{p} \mathrm{~d} V=0 .
\end{gathered}
$$




\section{Test Analysis of a High-Stress Rock Mass during Excavation Unloading}

Rock masses usually exist in a certain stress environment, and they are in a three-dimensional stress equilibrium state before excavation. In both TMB excavation and boreholeblasting excavation, the original balance is broken, forming a free surface on the rock mass, and the stress state transforms from the original three-dimensional six-sided stress into a three-dimensional five-sided stress, leading to the redistribution of stress in the surrounding rock. Stress concentration occurs in the surrounding rock near the free surface. When the secondary stress exceeds the bearing limit of the surrounding rock, the rock mass suffers failure. Therefore, the use of a unilateral unloading and loading method can more truly reflect the failure state of surrounding rock in practical engineering.

3.1. Test Equipment. The true triaxial disturbance unloading rock test system used in this study (see Figure 2) can expose a surface of the sample to simulate the phenomenon of a free surface occurring after excavation in underground engineering; this is achieved through an independent loading in three mutually vertical directions and sudden unloading in a single surface in the horizontal direction. In the vertical direction $(Z)$ of the system, the maximum load of the loading cylinder is $5000 \mathrm{kN}$; the disturbance cylinder is installed on the lower beam of the vertical loading frame, with a maximum dynamic load of $500 \mathrm{kN}$; the maximum loads of the two loading cylinders in the horizontal direction $(X, Y)$ are both $3000 \mathrm{kN}$; one of the cylinders is a dynamic cylinder, which is used for quick unloading; the loading and unloading are controlled by a fully digital servo controller, which provides the necessary means for determining the stress state of the rock mass when it suffers failure.

3.2. Test Scheme. This test mainly simulates the stressconcentration failure test of unilateral unloading under a true triaxial, three-dimensional, and hexahedral stress state. A cuboid marble with good integrity and uniformity was used as the rock sample; it had an initial density of $2758 \mathrm{~kg} / \mathrm{m}^{3}$, a water content of $0.02 \%$, and a size of $100 \mathrm{~mm} \times 100 \mathrm{~mm} \times$ $200 \mathrm{~mm}$.

3.2.1. Conventional Uniaxial Compression Test. To obtain the conventional compressive strength, deformation parameters, and failure characteristics of the marble, and to serve as a reference for the unilateral unloading and loading tests under true triaxial, three-dimensional, and hexahedral stress states, the confining pressure of sample \#1 was designed to be zero in this test (see Table 1). To better observe the variation in the postpeak curve, the deformation mode was used for loading in the test (see Figure 3(a)), with a loading rate of $0.05 \mathrm{~mm} / \mathrm{min}$ and $\sigma$ as the stress.

\subsubsection{Unilateral Unloading Stress-Concentration Failure} Test. When simulating deep tunnel excavation, the surrounding rock that is originally in the three-dimensional stress state develops a free surface, and the mutual extrusion of the surrounding rock in the tangential direction inten-

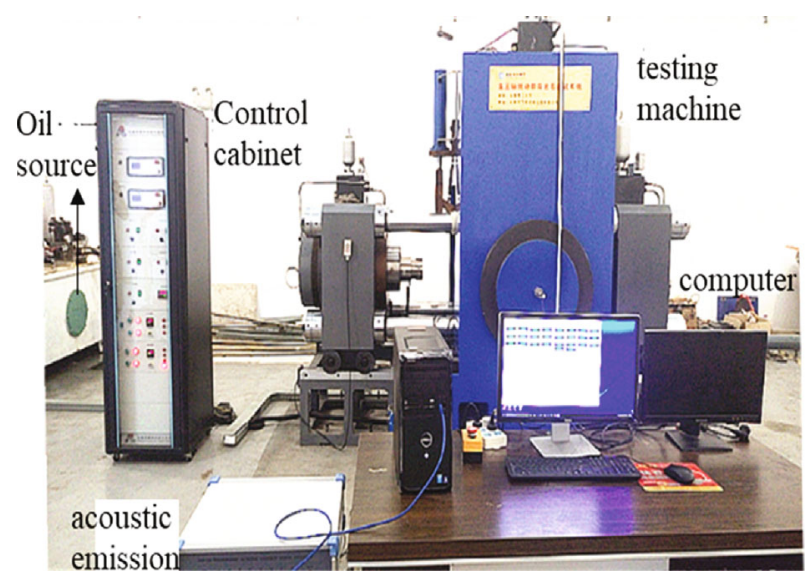

Figure 2: True triaxial disturbance unloading rock test system (Figure 2 is reproduced from $\mathrm{Xu}$ et al. [28]).

TABLE 1: Initial stress values.

\begin{tabular}{lccc}
\hline Sample number & $\sigma_{1}$ & $\sigma_{2}$ & $\sigma_{3}$ \\
\hline$\# 1$ & 0 & 0 & 0 \\
$\# 2$ & 50 & 5 & 2.5 \\
$\# 3$ & 50 & 10 & 5.0 \\
$\# 4$ & 50 & 20 & 10.0 \\
$\# 5$ & 50 & 30 & 20.0 \\
\hline
\end{tabular}

sifies the failure caused by stress concentration. The samples used in this test are numbered from \#2 to \#5, and the loading was controlled by loading at a loading rate of $0.5 \mathrm{MPa} / \mathrm{s}$. The stress loading path during the test is shown in Figure 3(b). First, in the $X, Y$, and $Z$ directions, the load is applied at $0.5 \mathrm{MPa} / \mathrm{s}$ to the set initial stress level (see Table 1). After reaching the initial stress level, the stress remains unchanged in the $Y$ and $Z$ directions, and transient unloading was performed on a surface in the $X$ direction at a speed of $50 \mathrm{~mm} / \mathrm{s}$ (see Figure 4(b)). Then, loading was performed in the $Z$ direction at a speed of $0.5 \mathrm{MPa} / \mathrm{s}$ until failure.

3.3. Stress-Strain Curve. The stress-strain curve for the true triaxial third principal stress with different confining pressures continuing to be loaded after unilateral unloading is shown in Figure 5. Compared with rock sample \#1 without confining pressure failure, the stress-strain curve of the stress-concentration type has the following characteristics: in the case without confining pressure, the peak value is $88 \mathrm{MPa}$, and with the confining pressure increasing, the peak points increase to $151 \mathrm{MPa}, 162 \mathrm{MPa}, 200 \mathrm{MPa}$, and $264 \mathrm{MPa}$, respectively. The prepeak curve also shows notable yield points. With the increase in the confining pressure, the yield point and the peak point increase, and the slope of the curve between the yield point and the peak point is moderate. The corresponding failure phenomenon is the splitting failure in the free surface and the potential shear failure in 


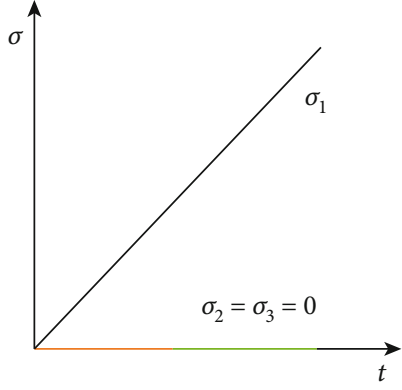

(a)

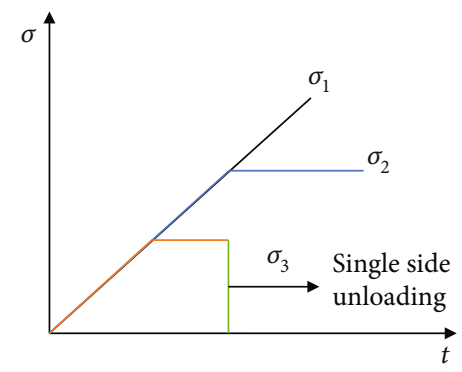

(b)

FIgURE 3: Test loading and unloading path diagram.

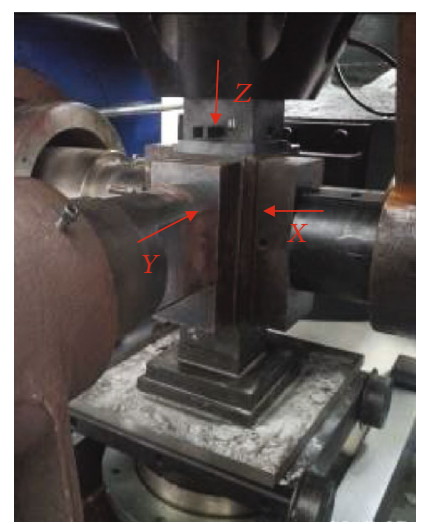

(a) Loading

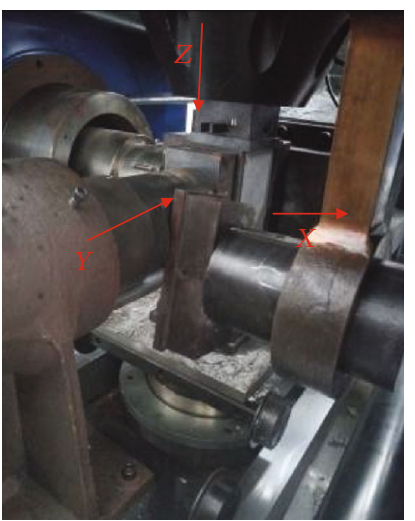

(b) Unilateral unloading

FIgURE 4: Spatial position of rock samples.

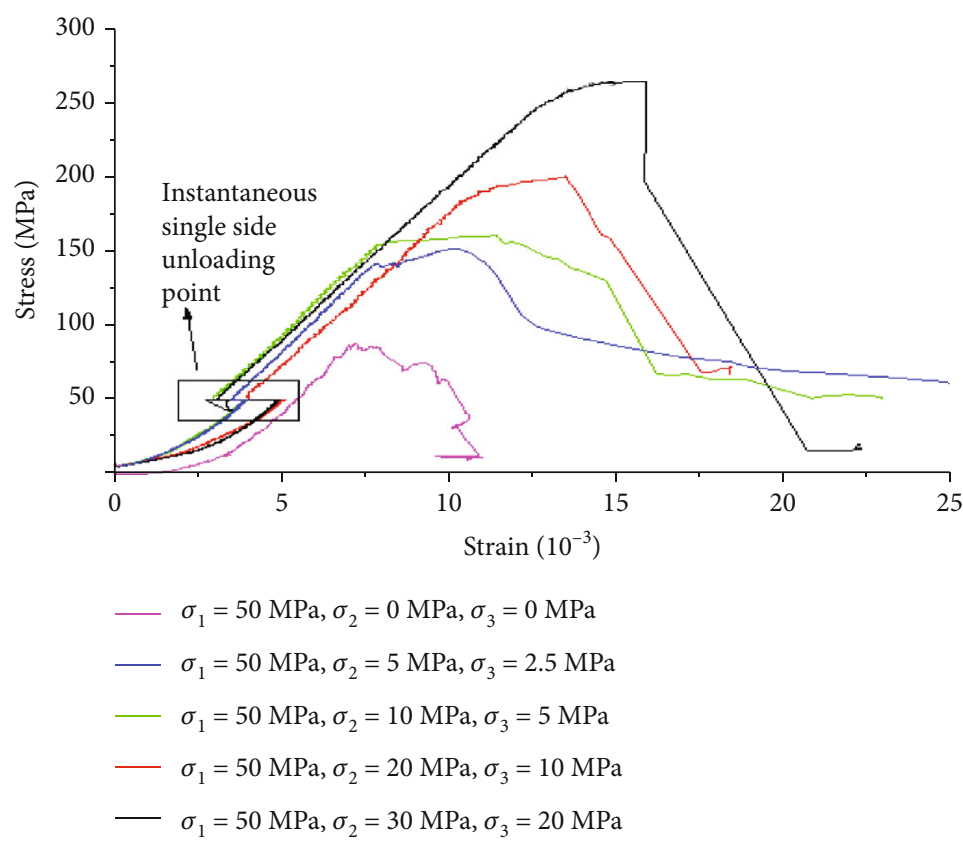

FIGURE 5: Stress-strain curve for stress-concentration failure under unilateral unloading. 
the rock mass. The axial strain before the peak is larger than that after the peak, and the postpeak stress after the peak shows a brittle drop. The postpeak stress-strain curve is relatively steep and inclined. When the confining pressure is $30 \mathrm{MPa}$ and $20 \mathrm{MPa}$, the postpeak curve is the steepest and the postpeak strain is the smallest. This shows that with an increase in the confining pressure, the failure changes from composite tensile-shear failure to splitting failure; with an increase in the confining pressure, the failure of the samples is the most severe, and the intensity of the rock burst is greater.

\subsection{Failure Characteristic Analysis}

3.4.1. Conventional Uniaxial Compression Test. In conventional uniaxial compression tests, the macroscopic failure type of marble samples is mainly a composite splittingshear failure (as shown in Figure 6). Because marble is a hard rock and has a relatively high brittleness coefficient, under the condition of no confining pressure, the lenticular angle of the cubic sample experiences a boundary constraint effect. In the failure process, there is a splitting failure surface at the upper part of the rock samples, which is almost parallel to the first principal stress surface. After failure, a peeling surface forms on the rock sample. There is a master shearing surface at the lower part of the rock sample, on which there is a large quantity of scratches and small fragments and powders of the rock sample. This is due to the secondary shear failure caused by stress concentration at resistance to load in the process of shear slip.

\subsubsection{Unilateral Unloading Stress-Concentration Failure.} After the rock sample is maintained for a certain period of time from triaxial compression to the initial state, rapid unloading is performed on the unilateral third principal stress, and the rock sample is in the stage of microcrack development. The number of microcracks increases, but no macroscopic cracks occur on any of the rock samples. Afterward, loading continues to be performed on $\sigma_{1}$; when it is loaded to $70 \%$ of the failure peak, after plate crack and ejection occurs on the \#2 \#5 rock samples, plate failure occurs on the free surface, with the generation of fine white rock powder. Two larger shear oblique cracks appear inside the rock mass, and a large amount of fine white rock powder appears in the cracks. With the increase in the axial stress, the plate crack width increases, and the rock sample reaches the final failure mode (see Figure 7). The slabby splitting of the rock mass is dominated by a tensile fracture, with a local shear stress. It is a progressive failure process of splitting into plates, followed by cutting into blocks, and then the ejection of blocks and pieces. This indicates that in the unilateral unloading process of $\sigma_{3}$ and $\sigma_{2}$ restricts the lateral expansion of the rock samples under the action of $\sigma_{1}$, leading to the development of rock samples towards the free surface. The continuous deformation causes the rock samples to transform from a state of compression to tension. When the tensile strength is reached, longitudinal cracks running through the rock samples are generated near the unloading surface, and rock

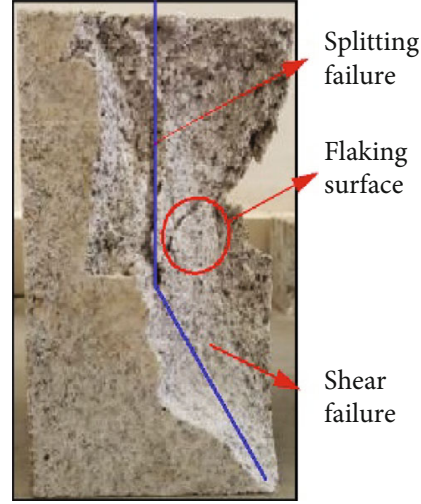

Figure 6: Macroscopic failure diagram for conventional uniaxial compression.

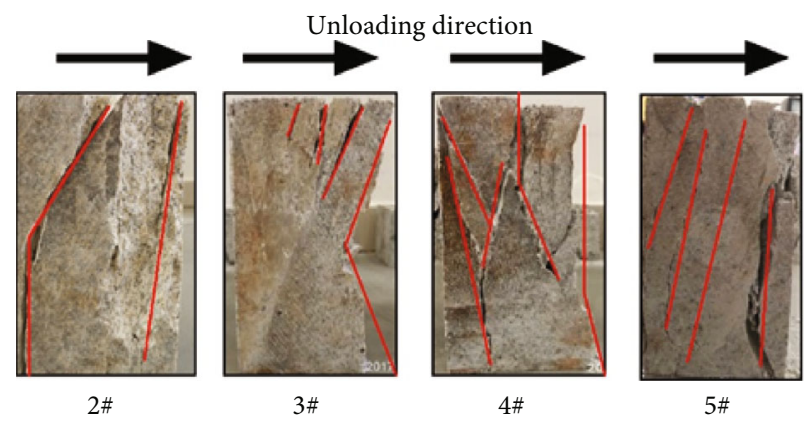

Figure 7: Schematic diagram for unilateral unloading stress concentration macroscopic failure.

plates parallel to the unloading surface form. With the continuous unloading of the unloading surface, the rock slab reaches the critical buckling value, and with the release of excess energy, rock burst failure occurs. The morphology of the rock samples after failure is shown in Figure 7. The \#2 \#5 rock samples all suffer plate cracks on the free surface, showing the three types of sheet shape, thin-plate shape, and wedge shape. This indicates that tensile failure occurs under true triaxial unilateral unloading conditions with confining pressure. With the increase in the confining pressure, the failure of rock samples shows dual characteristics, with tension failure occurring first followed by compression-shear failure. $\mathrm{V}$-shaped failure pits appear on the free surface, and penetrating shear fractures appear in the areas far away from the free surface. When the confining pressure increases to a certain extent, the rock samples suffer splitting failure, and splitting and penetrating cracks form over the entire rock mass. This shows that in the excavation process of a deeply buried roadway with high crustal stress, the two sides will show an instantaneous "unloading" effect, with instantaneous rebound deformation occurring. With the stress redistribution and stress concentration in local regions, when the tensile strength of the surrounding rock is exceeded, accidents such as plate cracks, rib spalling, and rock bursts will gradually occur on the two sides. 


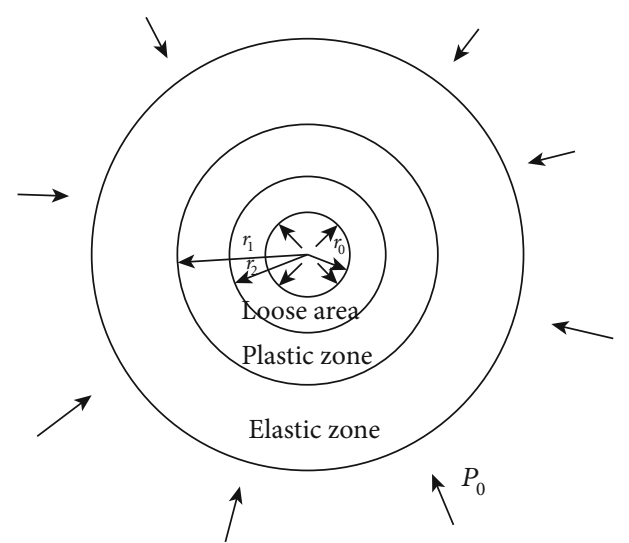

(a)

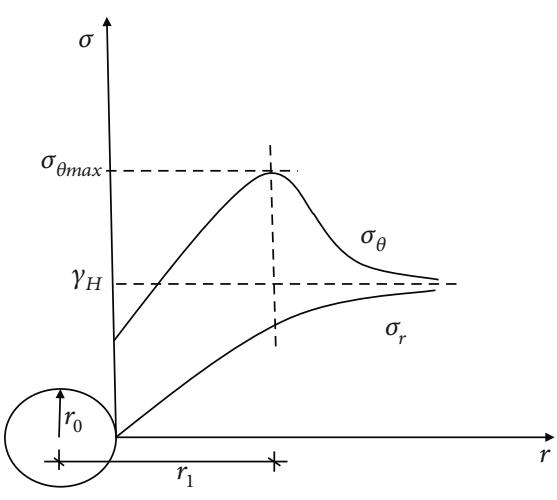

(b)

FIGURE 8: Stress distribution in rock mass around the roadway.

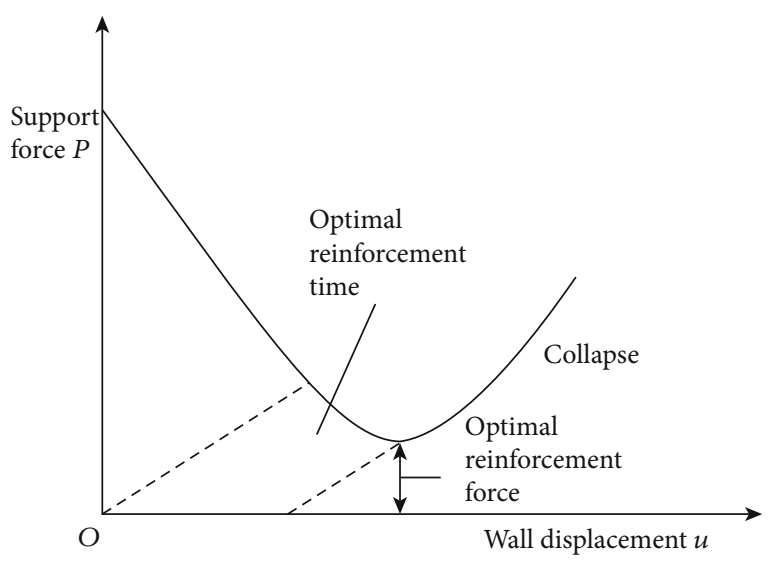

FIGURE 9: Diagram for the reasonable supporting time of surrounding rock.

\section{Reasonable Supporting Time for Surrounding Rock of a High-Stress Rock Mass Under Excavation Unloading}

After the excavation of a high-stress rock mass, with time, the bearing capacity of the surrounding rock itself decreases, creating a fractured zone with both depth and breadth. The stress concentration is caused by the bearing capacity of the rock mass itself. When the local high stress generated by the stress concentration exceeds the strength of the rock mass, the rock mass will deform towards the excavation surface, thus leading to failure. From the excavation surface to the deep part, it can be divided into three zones: failure zone (completely losing bearing capacity), plastic zone (having certain bearing capacity), and elastic zone (having intrinsic bearing capacity) (as shown in Figure 8). To reduce the range of the failure zone and the plastic zone and reasonably control the deformation of the surrounding rock, it is necessary to support the surrounding rock in a timely manner. According to the basic principle of NATM construction, as shown in Figure 9, selecting the best supporting time is the key after roadway excavation.

The number of time steps is the number of iterative steps calculated through numerical simulation, and it is the number of steps needed to be calculated in the process of establishing the stress balance of surrounding rock. However, the measurement unit used in the actual construction is time. The establishment of the relationship between time and the number of steps facilitates the numerical simulation results to guide the site construction better and more effectively. In the process of numerical simulation, when the displacement field, stress field, and plastic zone do not change with the increase in the time steps, the calculation reaches equilibrium, and the surrounding rock reaches the equilibrium and stable state. In the excavation process of a high-stress rock mass, the effect of each excavation unloading on the displacement field, stress field, and plastic zone is the key factor for guiding the site construction. When the calculation reaches the equilibrium state, it indicates that the effect of excavation unloading ends. According to the displacement curve of the surrounding rock deep in the roof during roadway excavation in numerical simulation, the relationship between the number of time steps required to achieve surrounding rock stability and the excavation distance can be determined through

$$
y=656.4791+\frac{(50.15365-656.4791)}{(1+\exp ((x-6.5871) / 1.81038))} R^{2}=0.99585 .
$$

4.1. Determination of Reasonable Reinforcement Time. The meaning of reasonable reinforcement time is the time corresponding to maximizing the bearing capacity of the plastic zone without loosening failure occurring. 3DEC was used to conduct numerical simulation on the roadway excavation process to monitor the curves of the change of the convergence quantity and convergence rate of the surrounding rock at the top and sides of the roadway with time, as shown in Figure 10. It basically reflects the movement and 

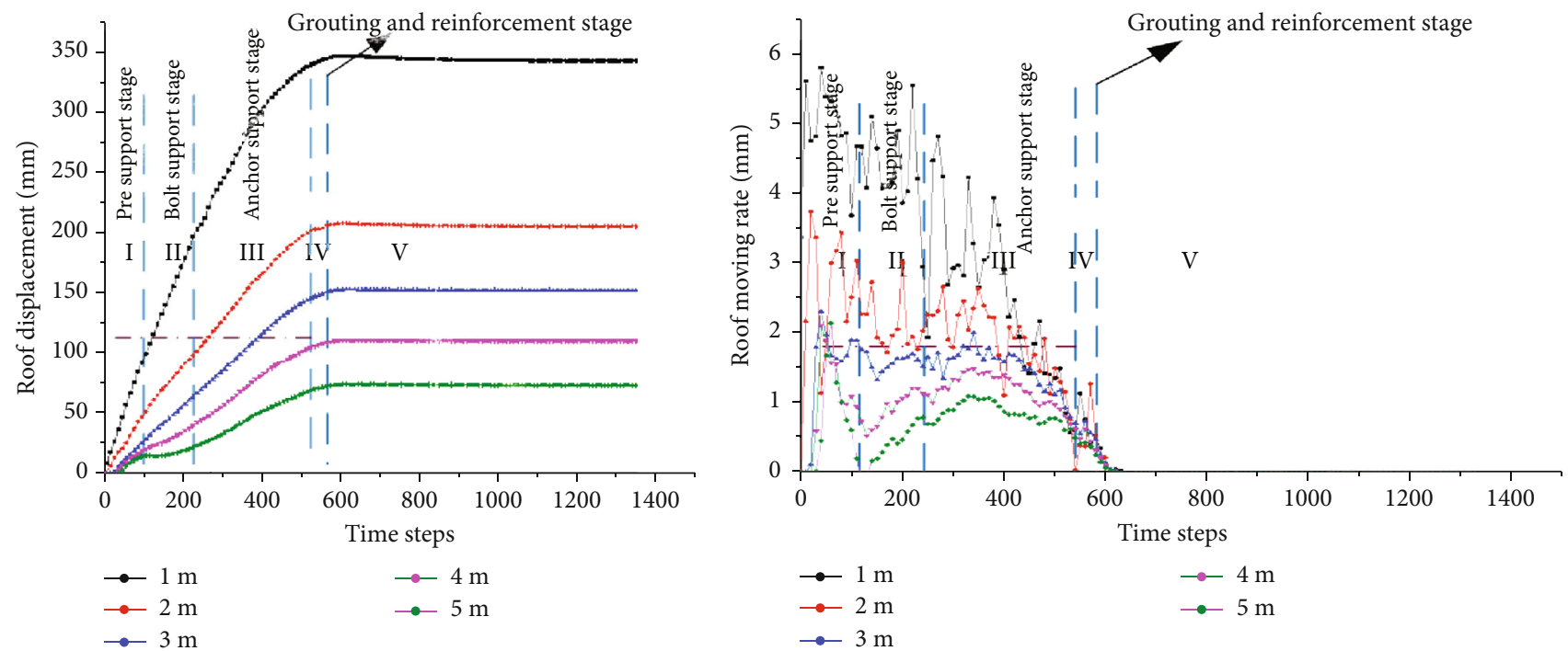

(a) Displacement curve for surrounding rock in deep roadway roof

(b) Changing curve for the convergence rate of surrounding rock in deep roadway roof

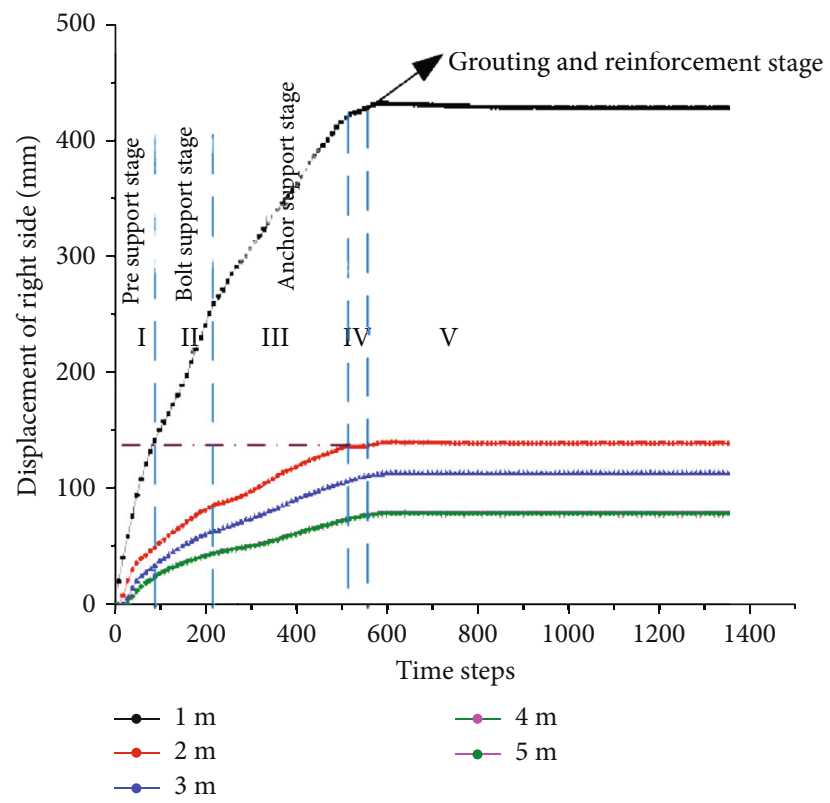

(c) Displacement curve of surrounding rock deep on the right side of the roadway

Figure 10: Continued. 


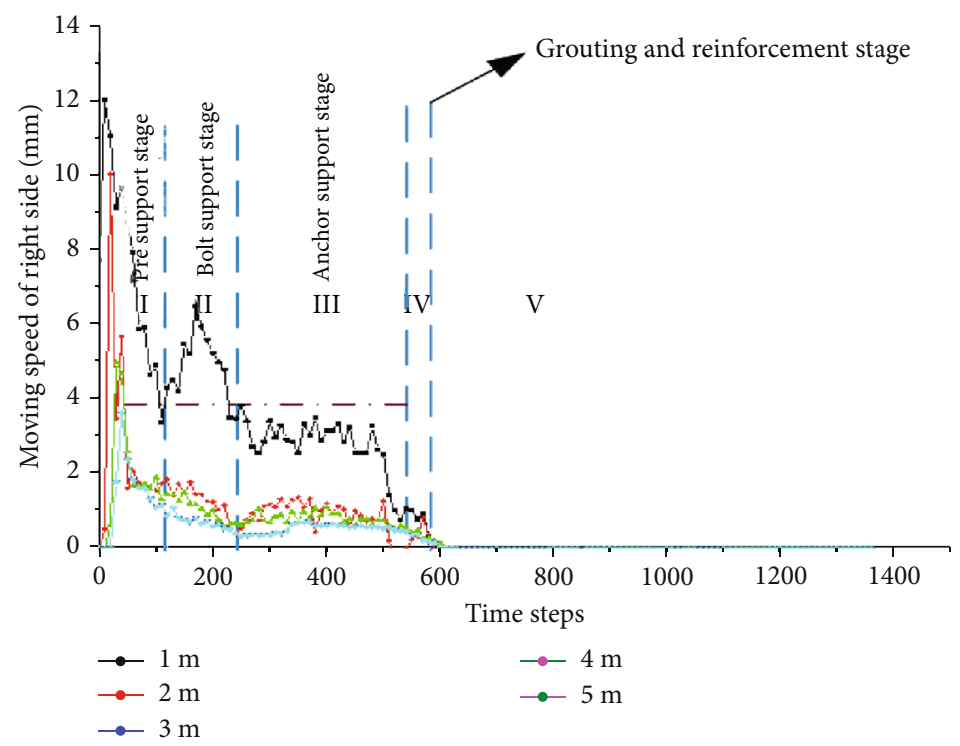

(d) Change curve of the convergence rate of surrounding rock deep on the right side of the roadway

FIGURE 10: Corresponding curves for the number of time steps and surrounding rock deformation of the roadway.
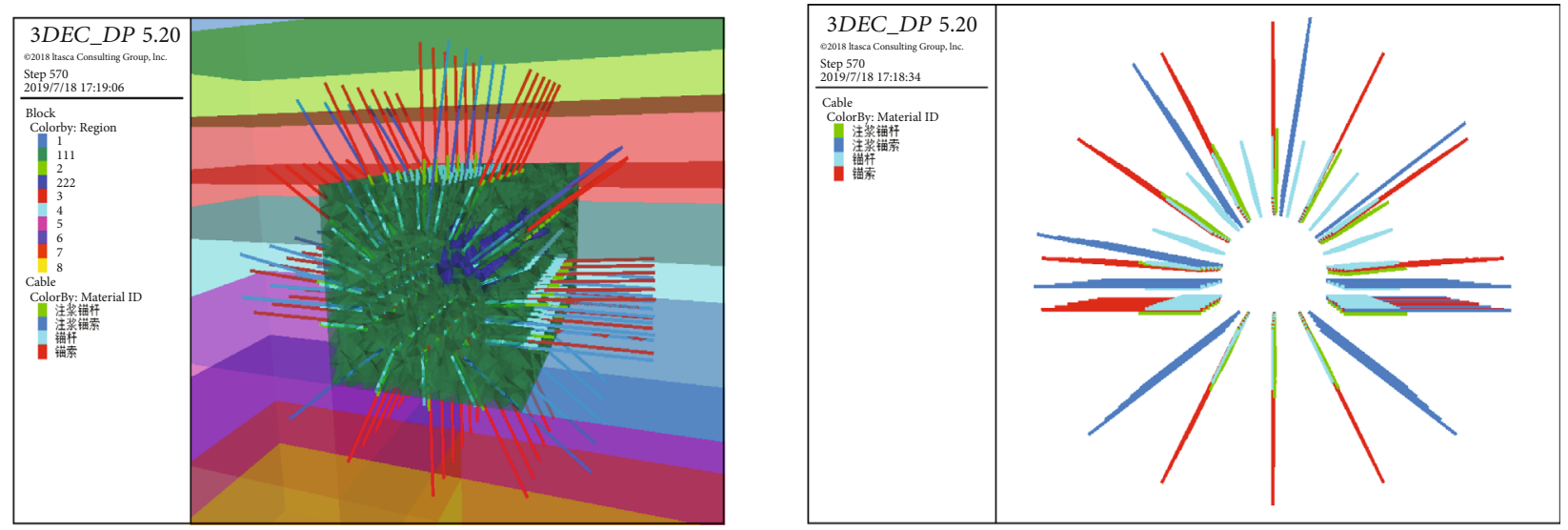

Figure 11: Numerical simulation diagram for support.

deformation of the surrounding rock. Reasonable reinforcement and supporting time should be the corresponding time when the surrounding rock displacement tends to be relatively stable.

As can be seen from Figure 10, due to the influence of roadway excavation, the surrounding rock within $1 \mathrm{~m}$ away from the roadway roof is severely deformed and broken into blocks, showing large deformation, and the final deformation reaches $452 \mathrm{~mm}$. Due to the inherent loadbearing capacity of the surrounding rock in the plastic zone, the surrounding rock that is $1 \mathrm{~m}-4 \mathrm{~m}$ away from the roadway roof is subjected to a declining convergence amount and convergence rate from the inner side to the outer side. The convergence amount of the surrounding rock within the range of $4 \mathrm{~m}$ to $5 \mathrm{~m}$ from the roof is basically the same. Therefore, it can be seen that, in the case with no support, the surrounding rock within $3 \mathrm{~m}$ and over $4 \mathrm{~m}$ from the roof shows a bed-separation phenomenon. Similar results can be obtained from the curves for convergence amount and convergence rate on the right side.

Analyzing the convergence amount and convergence rate of the surrounding rock at the top and right side of the excavation roadway with high-stress rock mass shows that the deformation of the surrounding rock at the top of the roadway changes dramatically in the first 520 steps of roadway excavation, and the convergence rate of the surrounding rock also shows a sharp change. The convergence amount of the roof tends to be relatively stable after 620 steps. When the number of time steps is 112,236 , and 520 , the convergence rates of the surrounding rock of the roof all show the trend of increasing and decreasing, indicating that the plastic zone of the surrounding rock plays its own role of load-bearing during the time steps of $0-112,192$ 236, and 482-520; during this time, the convergence rate of 
displacement decreases. With the increase in the displacement, the rock mass within the plastic zone loses its bearing capacity. The convergence rate of the surrounding rock displacement increases. Similar results can be obtained from the change curves of convergence amount and convergence rate on the right side. Thus, it can be seen that the optimal supporting time can be divided into four stages: (I) presupport stage: controlling the convergence amount of the displacement of the rock mass on the roadway surface to prevent the rock mass on the roadway surface from suffering tensile failure; (II) bolt reinforcement stage: increasing the strength of the plastic zone in the roadway and improving the bearing capacity of the plastic zone; (III) anchor cable reinforcement stage: further increasing the strength of the plastic zone in the roadway, enhancing its inherent bearing capacity, and reducing the deformation of the surrounding rock; and (IV) grouting reinforcement stage: carrying out grouting reinforcement on the rock mass within the plastic zone in the roadway to ensure the long-term stability of the roadway.

4.2. Technical Scheme for Surrounding Rock Reinforcement and Support. After the excavation of a high-stress rock mass, with time, stress concentration will occur in the surrounding rock of the roadway, and stress release will occur within a certain range, making the surrounding rock suddenly suffer severe deformation and failure; this severe deformation and failure will gradually extend to the deeper parts of the surrounding rock.

Anchor bolt (mesh) support plays a positive role in improving the strength and stress state of surrounding rock. The higher prestress can improve the stress state and control the deformation of surrounding rock. The combination of anchor cable and anchor bolt can make the anchorage structure of the anchor bolt hang in the harder and more stable rock strata deep in the surrounding rock. Cement grout plays a bonding role and can penetrate the loose zone to improve the strength of the surrounding rock around a roadway. Therefore, an anchor mesh-cable-grouting reinforcement technology for deep roadways is proposed. The concept is as follows:

(1) The deformation characteristics of high-stress roadways show that their support cannot reach the goal in one step; providing support is a process requiring secondary support or multiple supports

(2) During roadway excavation, the surrounding rock can be permitted to suffer some loose deformation and release some deformation energy accumulated in the surrounding rock, but it is necessary to undertake measures like initial spraying to seal the surrounding rock in time

(3) Anchor bolt-cable support with high strength and high prestress can be carried out on the roadway in a timely manner

(4) According to the monitoring results, after the severe deformation stage of the roadway, grouting rein- forcement should be carried out on the surrounding rock of the roadway at the right time to strengthen the surrounding rock and improve its overall bearing capacity

According to the special conditions of the air return cross-hole in the No. 81 mining area of the Xinhu Coal Mine that has a kilometer-deep well, a corresponding support scheme is put forward as follows: Supporting parameters: GM22/2600-490 rebar high-strength anchor bolt is used as anchor bolt; the row spacing between anchor bolts is $800 \times$ $800 \mathrm{~mm}$, with a rectangular layout; the anchor rod tray is $200 \times 200 \times 10 \mathrm{~mm}$. Two rolls of the K2950 resin anchoring agent are used for each anchor bolt above the arch camber, and two rolls of the Z2950 resin anchoring agent are used for each anchor bolt at the sides. The anchor cable is prestressed steel strand anchor cable, with a specification of $\Phi$ $21.8 \times 7300 \mathrm{~mm}$; two rolls of the Z2950 type and one roll of the K2950 resin anchor agent are used for each anchor cable; the row spacing is set to be $1600 \times 1600 \mathrm{~mm}$; a 300 $\times 300 \times 15 \mathrm{~mm}$ anchor tray is used for matching with each anchor cable; and the lockset at the outcrop of the anchor cable is 150 250 mm. Two rolls of the Z2950 resin anchoring agent are used for each anchor bolt on the side. The metal mesh is processed using $\Phi 6.0 \mathrm{~mm}$ round steel, with length $\times$ width $=2400 \times 900 \mathrm{~mm}$, and mesh of $100 \times 100$ $\mathrm{mm}$ connected by hook, and with the stubble of $100 \mathrm{~mm}$. The full-face shotcrete is $100 \mathrm{~mm}$ thick, and the concrete strength is C20. Grouting anchor bolts are laid out on the full face, and grouting anchor bolts are processed by using $\Phi 25 \times 2800 \mathrm{~mm}$ steel pipe, with the row spacing between them being $1600 \times 1600 \mathrm{~mm}$. At $\ngtr 70 \mathrm{~m}$ lagging behind the tunnel face, grouting anchor bolts are set up, and grouting is carried out. P.O42.5-type ordinary Portland cement is used as the cement for grouting, with a water: cement ratio of $1: 1$ and a grouting pressure of $2 \mathrm{MPa}$. Parameters of the supporting grouting and anchor cable are as follows: a hollow mine anchor cable is used as the anchor cable for grouting, with a specification of $\Phi 22 \times 7000 \mathrm{~mm}$. The tray of the anchor cable is TPF $300 \times 300 \times 15 \mathrm{~mm}$, and the lockset at the outcrop of the anchor cable is $150 \sim 250 \mathrm{~mm}$. 5 anchor bolts are laid out in each row along the roadway, with a row spacing of $2400 \times 2400 \mathrm{~mm}$. Two rolls of the Z2950 resin anchoring agent are used for each anchor cable for the grouting. P.O42.5-type ordinary Portland cement is used as the grouting cement with a water: cement ratio of $1: 1$. At $\ngtr 140 \mathrm{~m}$ lagging behind the tunnel face, the grouting anchor cables are set up and grouting is carried out with a grouting pressure of $3 \mathrm{MPa}$.

4.3. Analysis of the Support Effect of Surrounding Rock. To obtain the deformation, failure, and stress distribution characteristics of the surrounding rock at the roof and floor and the two sides of a high-stress roadway, the mechanical characteristics of the surrounding rock of the roadway were analyzed through 3DEC numerical simulation as shown in Figure 11.

Three-dimensional failure field characteristics of the high-stress surrounding rock during excavation support. 


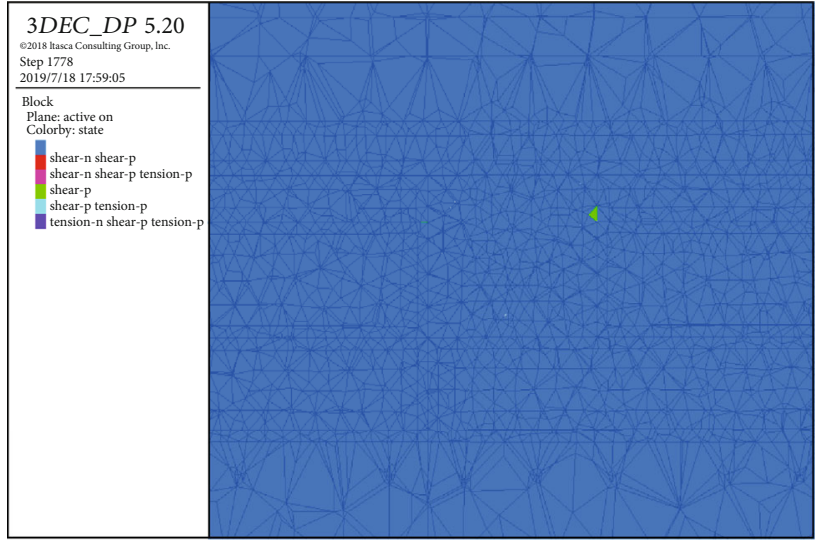

(a) $5 \mathrm{~m}$ in front of the tunneling face

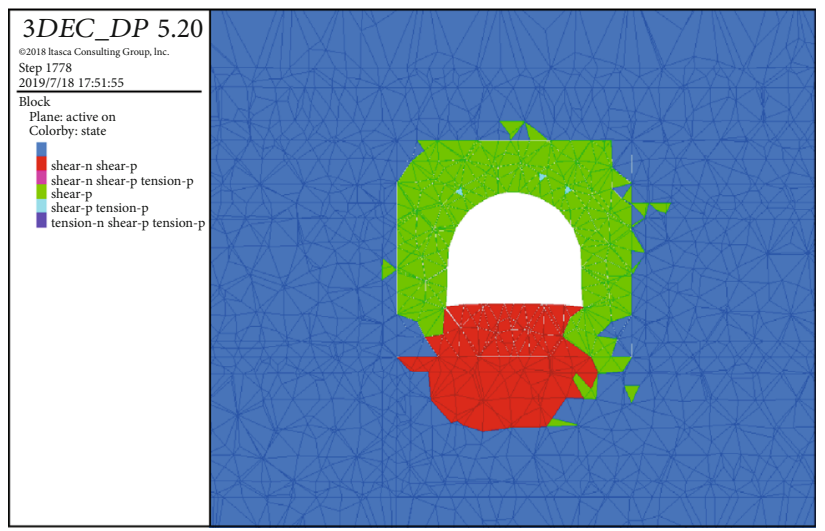

(c) $5 \mathrm{~m}$ behind the tunneling face

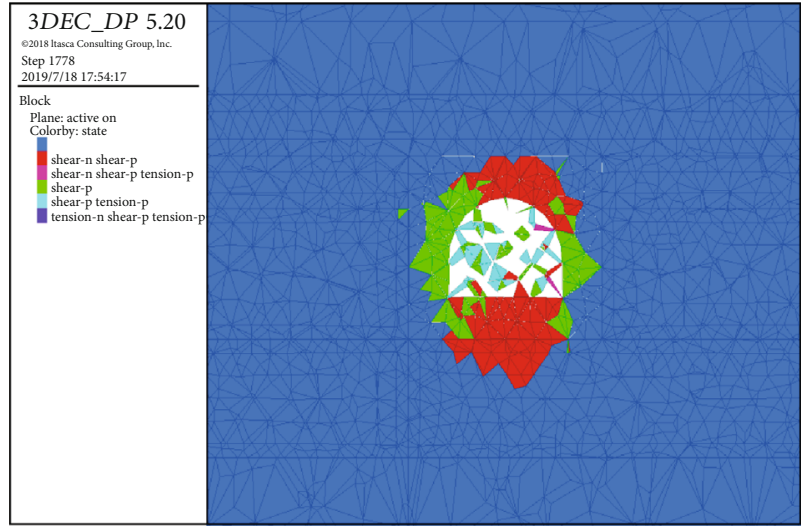

(b) At the tunneling face

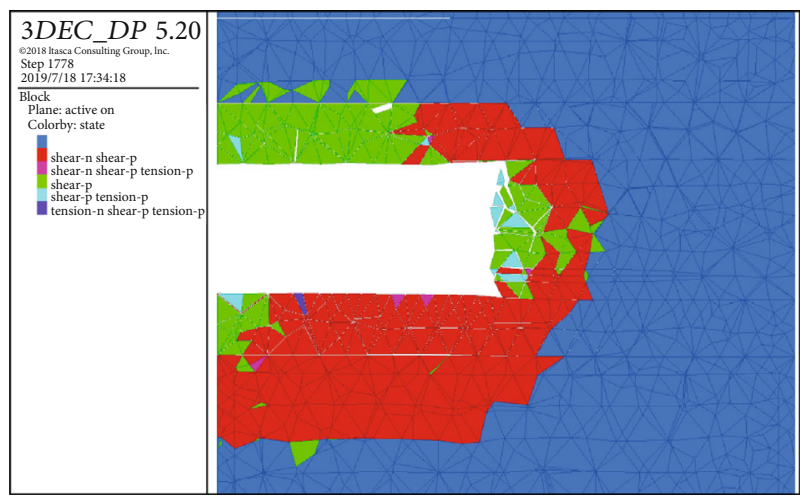

(d) Heading direction of tunneling

FIGURE 12: Diagram for the plastic zone of roadway excavation support.

Figure 12 shows the failure diagrams for the areas $5 \mathrm{~m}$ in front of the tunneling face, at the tunneling face, $5 \mathrm{~m}$ behind the tunneling face, and the heading direction of tunneling. As can be seen from the figure, although the rock mass $5 \mathrm{~m}$ away from the tunneling face has not been excavated, the rock mass suffers failure due to the support factor.

After the roadway is excavated, the surrounding rock suffers failure quickly in a wide range under the action of high stress, but the deformation of the surrounding rock is restricted by the support. In the area within $5 \mathrm{~m}$ behind the tunneling face, the plastic zone of the surrounding rock in the entire surrounding rock roadway no longer expands, forming a circular plastic zone with an approximate radius of $2.2 \mathrm{~m}$, which is $7 \mathrm{~m}$ smaller than that in the case without support. In the roadway, more than $5 \mathrm{~m}$ behind the tunneling face, the plastic zone range at the side no longer expands, but the plastic zone of the floor still continues to expand, and the final plastic zone range of the floor reaches $5.9 \mathrm{~m}$, which is $2.6 \mathrm{~m}$ smaller than that in the case without support.

4.4. Field Feedback on the Excavation Support Effect of Surrounding Rock. In this study, the deformation and failure characteristics of a high-stress rock mass were obtained through true triaxial tests on different loading paths.

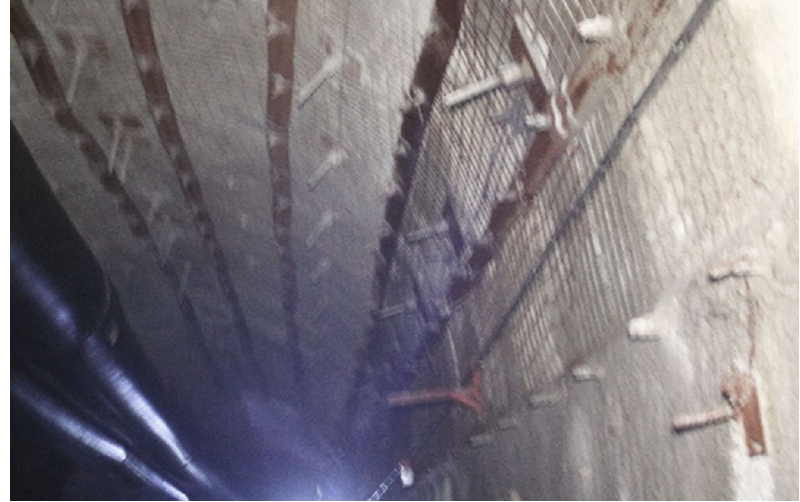

FIGURE 13: Field support drawing.

According to the deformation reinforcement theory, a composite support scheme of anchor mesh and cable shotcrete +shallow and deep hole grouting is designed and proposed, and the support effect was verified through numerical simulation. Through field practice, with the support field drawing shown in Figure 13, the reliability of the test results was verified, which serves as a reference for related projects. 


\section{Conclusion}

(1) True triaxial tests were carried out to compare and analyze the conventional uniaxial compression test results of a high-stress rock mass and the unilateral unloading stress-concentration failure tests; we obtained the progressive failure process of the surrounding rock, in which the failure characteristics of the rock mass under conventional uniaxial load is a composite splitting-shear failure, while the unilateral unloading stress-concentration failure characteristic follows the process of splitting into plates, followed by cutting into blocks, and then the ejection of blocks and pieces

(2) The roadway tunneling process was simulated through numerical simulation to obtain a reasonable reinforcement time for surrounding rock. It can be divided into four stages, i.e., the presupport stage, the bolt reinforcement stage, the anchor cable reinforcement stage, and the grouting reinforcement stage

(3) Under reasonable support, the plastic zone of the entire surrounding rock forms a circle of approximately $2.2 \mathrm{~m}$, which is $7 \mathrm{~m}$ smaller than that without support. The plastic zone at the side no longer expands, but the plastic zone of the base plate still expands, finally reaching $5.9 \mathrm{~m}$, which is $2.6 \mathrm{~m}$ smaller than that without support. The deformation is significantly reduced

\section{Data Availability}

The datasets generated and analyzed during the current study are available from the corresponding author on reasonable request.

\section{Conflicts of Interest}

The authors declared no conflicts of interest.

\section{Acknowledgments}

This study was supported by the National Natural Science Youth Fund (52004006) and Talent Fund of AUST (13200013).

\section{References}

[1] R. Yang, Z. Ye, L. Yongliang, and L. Weiyu, "Stability analysis and control measures of open roof roadway with hard roof," Journal of Mining and Safety Engineering, vol. 37, no. 5, pp. 861-870, 2020.

[2] B. Yingyun, W. H. Ning, and J. M. Jing, "Discrete element study on unloading dynamic failure mechanism of deep jointed rock mass excavation," Journal of Geotechnical Engineering, vol. 42, Supplement 2, pp. 196-201, 2020.

[3] S. Yonghua, H. Manchu, and G. Qian, "Rosenblueth method in the evaluation of bolting and shotcrete support system of soft broken surrounding rock," Journal of Geotechnical Engineering, vol. 3, pp. 378-382, 2004.

[4] T. Hongming, C. Weizhong, T. Xianjun, W. Hui, and T. Tian, "Study on reasonable support scheme of high ground stress soft rock tunnel," Journal of Rock Mechanics and Engineering, vol. 30, no. 12, pp. 2285-2292, 2011.

[5] C. Xiaoping, W. Feipeng, W. Bo, and L. Ziyang, "Experimental study on reasonable support scheme of high ground stress soft rock tunnel," Journal of railway engineering, vol. 35, no. 7 , pp. 65-71, 2018.

[6] Z. Guangming, X. Wensong, M. Xiangrui, and L. Chongyan, "Instability mechanism of high stress rock mass excavation unloading induced by disturbance," Acta coalae Sinica, vol. 45, no. 3, pp. 936-948, 2020.

[7] Z. Xi, L. Shaojun, D. Xu et al., "Study on deformation and stability of surrounding rock during initial excavation of main powerhouse of Shuangjiangkou hydropower station," Journal of rock mechanics and engineering, vol. 40, no. 3, pp. 520532, 2021.

[8] C. Wenzhuo, L. Xibing, Z. Zilong, Y. Haiwang, and W. Hao, "Energy dissipation law of excavation disturbance in high stress hard rock," Journal of Central South University (NATURAL SCIENCE EDITION), vol. 45, no. 8, pp. 2759-2767, 2014.

[9] H. Wu, Z. Nong, W. Wang, and G. Peng, "Deformation characteristics simulation and control technology of deep inclined rock roadway," Journal of Hunan University of Science and Technology (NATURAL SCIENCE EDITION), vol. 28, no. 1, pp. 6-12, 2013.

[10] Z. Baihong, H. Lijun, H. Guilei, and W. Yangning, "Three dimensional in-situ stress measurement and stability study of deep roadway," Geotechnical Mechanics, vol. 9, pp. 25472550, 2008.

[11] G. Panfeng, W. Sijiang, and Z. Sheng, "Simulation study on tunnel stability under different levels of stress," Journal of mining and safety engineering, vol. 27, no. 2, pp. 143-148, 2010.

[12] L. Jie, S. Chunming, X. Hu, C. Wentao, and F. Pengxian, "Analysis of deformation and failure mechanism of surrounding rock of deep roadway," Geotechnical Mechanics, vol. 33, Supplement 2, pp. 365-370, 2012.

[13] X. Yang, W. Mao, E. Wang, Y. Sun, J. Wang, and M. He, "Mechanism and control methods of roof deformations in gob-side entry retention by roof cutting under medium-thick coal seams," Geotechnical and Geological Engineering, vol. 38, no. 1, pp. 265-282, 2020.

[14] R. Yao, "Study on the relationship between roadway support time and surrounding rock grade," Mine Pressure and Roof Management, vol. 4, pp. 11-13, 2003.

[15] Z. Han, Y. Huang, J. Li, S. Zayzay Jr., and H. Gao, "Study on key parameters of roof cutting and pressure release in medium-thickness coal seam," Geotechnical and Geological Engineering, vol. 37, no. 4, pp. 3413-3422, 2019.

[16] W. Xu, Z. Guangming, M. Xiangrui, L. Yingming, C. Jinlong, and Gaoliang, "Experimental study on loading and unloading of marble under true triaxial single side unloading," Journal of Southwest Jiaotong University, vol. 54, no. 3, pp. 526-534, 2019.

[17] H. Da, Q. Tan, and H. Runqiu, "Mechanism of strain energy transformation process of marble damage and fracture under high stress and strong unloading," Journal of rock mechanics and engineering, vol. 31, no. 12, pp. 2483-2493, 2012. 
[18] D. Chunliang, Z. Guangming, L. Yingming, M. Xiangrui, L. Xiaoyu, and Z. Liyang, "Mechanical characteristics and failure mechanism of surrounding rock during excavation and unloading of deep circular roadway," Journal of mining and safety engineering, vol. 34, no. 3, pp. 511-518, 2017.

[19] A. Li, F. Dai, Y. Liu, H. Du, and R. Jiang, "Dynamic stability evaluation of underground cavern sidewalls against flexural toppling considering excavation-induced damage," Tunnelling and Underground Space Technology, vol. 112, p. 103903, 2021.

[20] J. Ruochen, D. Feng, L. Yi, and L. Ang, "Fast marching method for microseismic source location in cavern-containing rockmass: performance analysis and engineering application," Engineering, vol. 4, 2021.

[21] A. Li, Y. Liu, F. Dai, K. Liu, and M. Wei, "Continuum analysis of the structurally controlled displacements for large-scale underground caverns in bedded rock masses," Tunnelling and Underground Space Technology, vol. 97, p. 103288, 2020.

[22] S. Kai, Z. Yanjun, H. Wu, and Z. Li, "Study on evolution characteristics of safety factor of surrounding rock and selection method of support time during tunnel excavation," Journal of rock mechanics and engineering, vol. 38, Supplement 1, pp. 2964-2975, 2019.

[23] Z. Jian, J. Hu, H. Wang, and X.'a. Yang, “Mechanical research on reasonable supporting time of step by step support for deep tunnel," Engineering mechanics, vol. 36, no. 12, pp. 145-152, 2019.

[24] S. Yi and Z. D. Li, "Synergism principle of complex tunnel supporting structure system," Engineering mechanics, vol. 33, no. 12, pp. 52-62, 2016.

[25] F. Yu, Study on mechanical properties of interaction system between tunnel support and surrounding rock, Beijing Jiaotong University, 2017.

[26] D. F. Ting, Supporting theory and application technology of roadway surrounding rock loose circle, Coal Industry Press, Beijing, 2001.

[27] H. Chaojiong, G. Lisheng, and G. Panfeng, Bolt Support of Coal Roadway, China University of mining and Technology Press, Xuzhou, 1999.

[28] W. Xu, G. Zhao, X. Meng et al., "Effects of unloading rate on energy evolution mechanism in the single-side unloading failure of highly stressed marble," Advances in Civil Engineering, vol. 2020, 11 pages, 2020. 